\title{
EL DIFÍCIL PROCESO DE CREACIÓN DEL INSTITUTO DE VACUNACIÓN \\ DEL ESTADO (1871-1877)*
}

\author{
Ricardo Campos Marín \\ Dpto. de Historia de la Ciencia. Instituto de Historia. CSIC. Madrid
}

\section{RESUMEN}

Hasta 1871, España no contó con un organismo estatal encargado de cultivar, difundir y controlar la vacuna antivariólica. En este trabajo se analizan los problemas de creación del Instituto de Vacunación del Estado que sufrió varias refundaciones y remodelaciones entre 1871-1877. Las principales dificultades a las que tuvo que hacer frente fueron de tipo administrativo y técnico.

PALABRAS CLAVE: viruela, vacunación, vacuna animal, España, siglo XIX.

\section{SUMMARY}

Until 1871 Spain did not have a public institution in order to culture, to popularize and to check smallpox vaccine. The present article analizes the creation of Instituto de Vacunación del Estado and problems, several foundations and reformations it suffered between 1871-1877. The characters of the main dificulties it faced were both administrative and tecnique ones.

KEY WORDS: smallpox, vaccination, animal vaccine, Spain, $19^{\text {th }}$ century.

\section{INTRODUCCIÓN}

El 24 de julio de 1871 se fundó el Instituto Nacional de Vacuna, también conocido como Instituto Nacional de Vacunación ${ }^{1}$. Su creación ponía fin a la falta de un organismo estatal encargado de controlar y coordinar la vacunación, abriendo aparentemente un nuevo periodo en la lucha contra la viruela.

* Este trabajo ha sido realizado en el marco del Programa Ramón y Cajal del MCyT (Convocatoria 2002).

1 El Real Decreto puede consultarse completo en «Parte Oficial», El Siglo Médico, 6 de agosto de 1871, $n^{\circ}$ 919, pp. 503-504. 
Hasta entonces la vacunación en España se había desarrollado gracias a iniciativas puntuales de la Corona, cuyo ejemplo más acabado fue la Real Expedición Filantrópica de la Vacuna², así como al voluntarismo e interés de distintos individuos e instituciones privadas y estatales, sin que hubiera una decidida voluntad política de promulgar una legislación que estructurara todo el proceso y que considerase la vacunación una cuestión de Estado ${ }^{3}$. En su lugar surgió un panorama caracterizado por la proliferación y dispersión de

2 La Corona se mostró muy interesada por la difusión de la vacuna en los territorios ultramarinos para lo que impulsó y financió la Real Expedición Filantrópica de la Vacuna. Ver al respecto: DíAz DE YRAOlA, G. (2003), La vuelta al mundo de la Expedición de la Vacuna (1803-1810), Facsímil de la edición de 1948 y versión inglesa traducida y editada por Catherine Mark, CSIC, Madrid; RAMírez MARTín, S. (1999), La mayor hazaña médica de la Colonia. La Real Expedición filantrópica de la vacuna en la Real Audiencia de Quito. Quito, Abya-Yala; RAMíreZ MARTín, S. ( 2002), La salud del Imperio. La Real Expedición Filantrópica de la Vacuna, Ed. Doce Calles, Madrid; Balaguer Perigüel, E; BAllester AÑon, R. (2003), En el nombre de los niños: La Real Expedición Filantrópica de la Vacuna (18031806), Asociación Española de Pediatría, s/l.

3 Desde la introducción de la vacuna en España en diciembre de 1800 por Piguillem, ésta se difundió gracias a la voluntad de los profesionales sanitarios y representantes de la burguesía, funcionarios del Estado, aristócratas y sacerdotes, movidos por la filantropía y también por intereses personales. OlAGÜE DE ROS, G. y Astrain GALlART, M. (1995), «Propaganda y filantropismo: Los primeros textos sobre la vacuna Jenneriana en España». Medicina e Historia. 56: I-XVI. Más allá de la mencionada Expedición de la Vacuna, el Estado no volvió a implicarse en su difusión. La única medida legislativa adoptada en este sentido, fue una Real Cédula de 1805 que obligaba a todos los hospitales a tener una sala de vacunación. En 1815, ante su reiterado incumplimiento se promulgó una Real Orden para que se cumpliera la Real Cédula. A este respecto véase: DIRECCIÓN GENERAL DE SANIDAD (1903), Datos históricos acerca de la vacuna en España. Leyes y Decretos contra la viruela, Madrid, Imp. Católica, La prensa de Madrid; SANTAMARÍA, E. (1990), «Las salas de vacunación en los hospitales peninsulares a principios del siglo XIX», Dynamis, 10, 303-311. Sobre la introducción de la vacuna en España puede verse: RUMEU DE ARMAS, A. (1940), «La inoculación y la vacunación antivariólica en España (Datos para la historia de la medicina española en los siglos XVIII y XIX)», Medicina Española, tomo IV, 19, 46-59; 20, 143-159; 21, 233-241, 22, 317-329; 392-410; OLAGÜE DE Ros, G.; Astrain, Gallart, M. (1994), «Una carta inédita de Ignacio Ruiz de Luzuriaga (1763-1822) sobre la difusión de la vacuna en España (1801)», Dynamis, 14, 305-337; OlAGüE DE ROS, G. (1995), «La introducción de la vacunación jenneriana en España (1799-1805)». En: Barona, J. L. (ed.), Malaltia i Cultura, València, Seminari d'Estudis sobre la Ciencia, 251-273. En los años que siguieron a la expedición, la única iniciativa que tuvo un carácter medianamente global fue la Comisión Central de Vacunación del Instituto Médico Valenciano, estudiada por $\mathrm{M}^{\mathrm{a}}$ José Baguena en otro artículo del presente Dossier. 
las iniciativas vacunadoras en el cual los intereses mercantiles y profesionales tuvieron un destacado papel que aumentaría con los años ${ }^{4}$.

La creación del Instituto parecía impulsar definitivamente la propagación de la vacuna al intentar suplir parcialmente algunas de las graves carencias que existían. Sin embargo, el proyecto tropezó con diversos escollos que impidieron su desarrollo normal, hasta el punto de sufrir varias refundaciones y cambios de nombre durante periodo $1871-1877^{5}$. Además nunca fue acompañado por una ley que se decantara hacia la obligatoriedad de la vacunación. Esta llegaría en 1903 cuando el Instituto había sido integrado como una sección dentro del recién creado Instituto Alfonso XIII ${ }^{6}$.

En el presente trabajo pretendo estudiar los primeros años del Instituto de Vacunación del Estado ${ }^{7}$ con el doble objetivo de analizar su difícil creación y colmar parcialmente el desconocimiento historiográfico que existe sobre el mismo. Mi punto de partida es que el Instituto de Vacunación del Estado no alcanzó sus objetivos fundacionales porque tropezó con graves dificultades de orden administrativo y técnico que impidieron su desarrollo. Los principales problemas administrativos fueron la competencia mercantil con otros institutos vacunadores públicos y privados; la falta de una legislación que apostara por la obligatoriedad de la vacuna; la escasa dotación económica y de personal que el Estado le asignó. En lo referente a los aspectos técnicos fueron especialmente significativos los problemas derivados de la obtención, conservación y distribución de la linfa vacunal; la tipología de vacuna que se pretendía aplicar; la existencia de enfermedades asociadas a la vacuna, y las resistencias de la población.

Las fuentes utilizadas para la elaboración de este estudio han sido la legislación, las memorias sobre la actividad del Instituto, los folletos, artículos de

4 Sobre estas cuestiones véanse: CAMPOS MARÍN, R. (2001), «La vacunación antivariólica en Madrid en el último tercio del siglo XIX. Entre el especialismo médico y el mercantilismo.» Medicina e Historia, 4: 1-15; CAMPOS MARÍN, R. (2004), «La vacunación en España durante la segunda mitad del siglo XIX. Problemas institucionales, controversias y actitudes populares». En: RAMirez S; VALENCIANo, L; NÁJERA, R; ENJuANES, L. (Edts) La Real Expedición Filantrópica de la Vacuna. Doscientos Años de Lucha Contra la Viruela, Madrid, CSIC. (en prensa).

5 El organismo pasó por distintos avatares y sufrió diversas refundaciones y cambios de nombre, aunque siempre mantuvo el mismo espiritu. Las denominaciones fueron Instituto Nacional de Vacuna (1871); Centro provisional de Vacunación (1875), Centro General de Vacunación (1876), Instituto de Vacunación del Estado (1877). .

6 Porras Gallo, Mª . I, «Antecedentes y creación del Instituto de Sueroterapia, Vacunación y Bacteriología de Alfonso XIII», Dynamis, 18, 1998, pp. 81-105.

7 Esta última denominación fue la que pervivió hasta su desaparición en 1899. Por ello es la que aparece en el título. 
prensa médica, así como la documentación manuscrita, conservada en el Archivo de la Real Academia de Medicina de Madrid ${ }^{8}$, compuesta mayoritariamente por cartas, borradores normativos, actividades de otras instituciones vacunadores, etc.

2. UN PRIMER INTENTO FALLIDO: LA CREACIÓN DEL INSTITUTO NACIONAL DE VACUNA EN 1871.

2.1. La disputa entre el Ministerio de Fomento y la Real Academia de Medicina.

Entre 1870 y 1871 confluyeron diversos factores que propiciaron la constitución de un organismo estatal de vacunación. El cambio de régimen político en septiembre de 1868 fue sin duda un elemento importante, pero la experiencia de la epidemia que asoló Francia en 1870 y la relevancia que tomó la cuestión de la vacuna y la viruela en el seno de la Academia de Medicina parecen haber sido determinantes en la concienciación de la administración ${ }^{9}$. No obstante, la iniciativa estatal de fundar el Instituto Nacional de Vacuna originó un conflicto con la Academia de Medicina, que mostró su desconfianza ante las decisiones del gobierno y su deseo de controlar plenamente el nuevo centro.

La cronología de los hechos ayuda a comprender la pugna que alimentó todo el proceso de creación del Instituto.

Un año y medio antes del Decreto de Fomento, la Academia acariciaba la idea de crear un centro propio. Así lo hizo saber el 18 de marzo de $1870 \mathrm{su}$ Junta de Gobierno al proponer que la Comisión de Vacunación ${ }^{10}$ de la misma fundase un Instituto de vacunación:

«Considerando esta Junta la inmensa importancia de las cuestiones relativas a la vacunación; considerando que convendría establecer un Instituto práctico de vacuna-

8 Quiero agradecer a Ignacio Díaz, bibiliotecario y archivero de la Real Academia de Medicina de Madrid su ayuda para localizar muchas de las fuentes que he utilizado para elaborar este trabajo.

9 MÉndez Alvaro, F. (1871), Discurso acerca de la preservación de las viruelas. Leido a la Real Academia de Medicina de Madrid por su socio numerario Dr. D...., Madrid, Imprenta y Esterotipia de M. Rivadeneyra.

10 Entre las comisiones de la Academia de Medicina estaba la Comisión de Vacunación, que estaba encargada de estudiar «las graves cuestiones relativas a este importante medio profiláctico». Ver Reglamento de la Real Academia de Medicina de Madrid, Madrid, Imprenta de Manuel Rojas, p. 20. 
ción a fin de tomar parte activa en la gestión de este ramo de la higiene pública que le está eficazmente recomendado por todos sus reglamentos: tiene el honor de proponer a la Academía que si existe el celo de la Comisión de vacunación a fin de que se sirva discutir y proponer un dictamen sobre la conveniencia, oportunidad y medios de llevar a cabo la idea de propagar prácticamente la vacunación y de iniciar una serie de experimentos y observaciones a propósito para esclarecer las diversas cuestiones que aun están pendientes de resolución, respecto de este privilegiado objeto» ${ }^{11}$.

Varios meses más tarde, el 20 de mayo de 1871, Francisco Méndez Álvaro retomaba la idea en su Discurso acerca de la preservación de las viruelas, considerando de gran interés que las naciones ordenasen un «buen sistema general de vacunación, extendido a todos los pueblos, con sus partes eslabonadas de suerte que concurran al armónico resultado común que se trata de realizar» ${ }^{12}$. En cuanto a la responsabilidad de organizar la vacunación, señalaba que si bien el gobierno debía impulsarla, las sociedades médicas podían «adelantar la idea e iniciar el movimiento», proponiendo abiertamente a la Academia de Medicina,

«fundar y sostener con sus propios recursos, y los que tenga a bien el Gobierno facilitarla — bajo la dirección inmediata de su Comisión de Vacunación, convenientemente reorganizada, y en conformidad con al proyecto de Reglamento que me cabe la honra de acompañar - un Centro de vacunación, destinado al fomento, cultivo y pefección de la vacuna» ${ }^{13}$.

Sus propuestas contaban con el beneplácito de la Academia, pues el Discurso era en buena medida un resumen de la amplia discusión que tuvo lugar en su seno sobre «Terapeútica y preservación de las viruelas» ${ }^{14}$. Un mes despues, el 22 de junio de 1871 la Academia dirigió una carta al Ministerio de Fomento, informando de su intención de poner en marcha un centro de vacunación. Los trabajos iban muy avanzados y se anunciaba que en breve se remitiría un proyecto de reglamento para su examen y aprobación por el Ministerio. Asi mismo, daba por sentado que dada la importancia del tema el «Gobierno de S.M.» prestaría «a la corporación los auxilios morales y materiales que le son necesarios para llevar a cabo esta empresa» ${ }^{15}$.

11 Esta información puede verse en el Archivo de la Real Academia de Medicina de Madria (ARAMM), Legajo 113. Documento 5106.

12 MÉndez Alvaro (1871), pp. 69-70. El Discurso, iba firmado con fecha de 20 de mayo aunque su publicación fue posterior.

13 Ibidem.

$14 \quad$ Ibid. pp. 5-6

15 ARAMM. Legajo 107. Documento 4723 (I). 
El proyecto de la Academia se vió truncado por la creación del Instituto Nacional de Vacunación. En el preámbulo, el Ministro de Fomento, Manuel Ruiz Zorrilla hacía una larga exposición de los motivos que movían al Gobierno a crearlo. El punto de partida era la gravedad de la situación originada por la persistencia de la viruela y su correlato de «grandes estragos en casi todas las provincias» ${ }^{16}$. A continuación trazaba los avatares históricos de la vacunación en España y sus dominios coloniales, aunque sin explicar porqué se había perdido aquel impulso inicial. En todo caso, más allá de la retórica de los argumentos históricos, apuntaba la necesidad de equipararse a otros países europeos que tenían centros de vacunación estatales para poder luchar contra la viruela:

«De tal importancia son algunas de estas cuestiones y tan urgente aparece su estudio, que hubiera creido el Ministro que suscribe que dejaba un lamentable vacio si no sometía a la aprobación de V.M. la creación de un Instituto nacional de Vacuna, imitando en este punto la conducta del mayor número de los Gobiernos de Europa. En Berlín, en Viena, en Nápoles, en Milán, en París, en Londres, en San Petesburgo, no solo en las capitales de los Estados, sino en poblaciones de segundo orden, existen Institutos de vacunación que con este $u$ otro nombre han hecho inmensos beneficios a la salud pública, demostrando de una manera indudable que la viruela es una epidemia que se combate con facilidad y que puede llegar a extinguirse» ${ }^{17}$.

El artículo $2^{\circ}$ marcaba que los cometidos del Instituto eran: estudiar y difundir los conocimientos sobre la viruela; estudiar, obtener y conservar vacuna; asesorar al Gobierno en las cuestiones relacionadas con la enfermedad y la vacunación, y dirigir las operaciones de vacunación y revacunación ${ }^{18}$. En el plano administrativo quedaba bajo la dependencia del Ministerio de Fomento, si bien su dirección se encomendaba a la Academia de Medicina.

La noticia fue recibida con frialdad por sectores importantes de la medicina. El Siglo Médico publicó dos artículos anónimos en los que mantenía una actitud distante hacia la medida y se alineaba con la Academia de Medicina, que sospechaba que el Ministerio se había apropiado de su iniciativa ${ }^{19}$. El

16 «Parte Oficial», El Siglo Médico, 6 de agosto de 1871, $n^{\circ}$ 919, p. 503.

17 Ibidem.

18 Ibidem.

19 Esta sospecha aparece en diversos textos de la época. Como botón de muestra véase Memoria que eleva al Gobierno el Centro General de Vacunación correspondiente al primer semestre del año de 1876, Establecimientos Tipográficos de M. Minuesa, 1876, p. 8, donde se afirma: «Si no tuvo entonces realización el acuerdo de la Academia, despertó quizá la idea que inspirara el mencionado Decreto de 24 de julio del mismo año. ¿Por qué ha de negársela esa 
primero de ellos, consideraba una irregularidad que Fomento legislara en «asuntos relativos a salud pública, correspondientes a Gobernación», y reclamaba que la redacción del reglamento se encomendara a la Academia, si realmente se deseaba «alcanzar una organización tal cual perfecta» ${ }^{20}$. El segundo recordaba la propuesta de la Academia, inspirada por Méndez Álvaro, de crear un centro de vacunación, celebrando con ironía el que ambas instituciones hubieran tenido «a la par» la misma idea ${ }^{21}$. A partir de entonces la Academia centró su estrategia en conseguir que el Ministerio le encargara la redacción del futuro reglamento del Instituto, consciente de que el control efectivo del nuevo organismo no pasaba sólo por detentar la dirección que el Decreto les otorgaba. No fue, sin embargo, un objetivo fácil de obtener y pasaron varios meses hasta que el Ministerio accedió a su petición. Ahora bien, todavía hubo algunos escarceos provocados por el deseo de los académicos de imponer el reglamento que habían elaborado para regentar su fallido centro vacunador. Tras la negativa del Ministerio, la Academia aceptó redactar uno nuevo, enviándolo para su aprobación en diciembre de 1871, aunque nunca obtuvo respuesta porque el Instituto Nacional de Vacuna no llegó a funcionar ${ }^{22}$.

\subsection{El proyecto de reglamento.}

La Comisión de Vacunación de la Academia fue la encargada de redactarlo, si bien el autor del texto fue Méndez Alvaro. El documento comenzaba con una serie de consideraciones generales que analizaban las dificultades que suponía organizar un organismo de ámbito estatal, pronunciándose por un proyecto más modesto que tuviera como ámbito de actuación Madrid ${ }^{23}$. Los

iniciativa, cuando la acreditan sus actas, la propuesta elevada entonces a la superioridad y un discurso resumen de sus sesiones, que corre impreso?»

20 «Instituto de vacunacion», El Siglo Médico, 6 de agosto de 1871, nº 919, p. 507.

21 «Mas sobre vacunacion», El Siglo Médico, 6 de agosto de 1871, n 919, p. 507.

22 La pugna puese seguirse en ARAMM. Legajo 107. Doc 4723 (I-VII). También en «Mas sobre vacunación», El Siglo Médico, 6 de agosto de 1871, nº 919, p. 507.

23 A comienzos de 1874, con motivo de la refundación del Instituto, El Siglo Médico lo publicó por si pudiera ser «de alguna utilidad su conocimiento (porque sobre lo ya pensado maduramente y formulado es facilísimo introducir perfecciones).» «Revista de la Semana. Instituto de Vacunación», El Siglo Médico, 4-I-1874, n 1045, p. 1. «Ya que tan laudable propósito no alcanzó a pasar de proyecto, — como en nuestro desgraciado país suele suceder a todos los pensamientos laudables de gobierno y administración - bueno es dar a conocer lo que se idea y pone, por si teniéndolo alguna vez presente en ocasión más propicia, puede 
principales obstáculos para erigir el Instituto eran la falta de presupuesto y la desorganización sanitaria del país:

«Cosa llana fuera sin duda organizar en Madrid un Centro de Vacunación como el que se propuso establecer la Academia al terminar la prolija discusión que el año anterior ocupó muchas de sus sesiones, toda vez que no faltaron los recursos para sostenerle; pero al tratar de hacer extensivo el servicio de vacunación a todo el reino según corresponde a un Instituto Nacional, y esto disponiendo tan sólo de los escasos recursos que sienten la penuria del Erario y el angustioso estado del país y hallándose por otra parte en la necesidad de utilizar los escasos, variados e inconexos elementos que de anteriores organizaciones sanitarias subsisten, olvidados algunos, o poco menos, y en notoria desarmonía otros, ya puede inferirse que sus vacilaciones y temores han debido subir hasta el límite del desaliento» ${ }^{24}$.

La declaración genérica de problemas se concretaba en una serie de cuestiones que los redactores del reglamento intentaban remediar «utilizando de la mejor manera (...) lo existente». La mayor traba era «la imposibilidad de crear en las provincias centros activos de Sanidad, que sirvieran para este propósito y otros de higiene pública (...) para formar en todo el territorio español una vasta red sanitaria subordinada a un solo pensamiento.» Para intentar alcanzar este objetivo Méndez Alvaro señalaba que se había utilizado,

«la defectuosa organización presente sin pararse siquiera a examinar la época de que procede cada parte de ese conjunto, ni el pensamiento que movió a su creación ni si tales ruedas engranan bien con la maquinaria administrativa que se halla en movimiento» ${ }^{25}$.

La vacunación se confiaba a las Juntas provinciales de Sanidad, a los subdelegados Médicos y a los facultativos titulares de los pueblos, vinculando la organización de un verdadero servicio de vacunación a « la ya secular empre-

lograrse perfección mayor cuando con formalidad se trate de realizar análogas empresas». «Folletin. Un Documento. Proyecto de Reglamento del Instituto Nacional de Vacunación», El Siglo Médico, $\mathrm{n}^{\circ}$ 1050, 8 de febrero de 1874, p. 81-84. El resto de reglamento se publicó en los números correspondientes al, 15 y 22 de febrero y en el del 15 marzo. Sin embargo, no se publicaron las consideraciones generales recogidas en el borrador conservado en el archivo de la Academia, que ofrecían un interesante análisis de las dificultades que suponía organizar un Instituto nacional de vacunación. ARAMM. Legajo 107. Doc 4723 (III).

24 ARAMM. Legajo 107. Doc 4723 (VII).

25 Ibidem. 
sa de dar a la Sanidad e higiene pública una organización a la altura de la época en que vivimos» ${ }^{26}$.

Por tanto, el documento era también una crítica a la estructura institucional de la sanidad del país y un alegato para su mejoría.

A los problemas de organización se añadían las dificultades pecunarias para pagar a los Subdelegados y a los facultativos vacunadores. A juicio de Méndez Álvaro era preciso arbitrar algún sistema de remuneración a dicho trabajo extraordinario para evitar el abandono de la vacunación por falta de estímulo. Para paliar este extremo, proponía que las Diputaciones y Ayuntamientos se hicieran cargo de dichas retribuciones, presupuestándolas anualmente, recurriendo así a una práctica muy extendida por el Estado liberal que consistía en delegar sus responsabilidades a las instituciones locales. Por último, se señalaban las enormes dificultades de registrar con exactitud los datos de vacunaciones y revacunaciones que obtuvieran los facultativos y las Asociaciones médicas libres ${ }^{27}$.

El reglamento propiamente dicho, tenía 86 artículos repartidos en 8 capítulos, que abordaban tanto aspectos científicos como administrativos.

Los doce primeros artículos consagraban una organización del Instituto extremadamente burocrática y poco operativa. Se contemplaba la creación de una Comisión de vacunación compuesta por once académicos, cuyo Presidente sería el director del Instituto. A su vez se creaban tres subcomisiones dedicadas respectivamente al estudio patológico de las viruelas, de la vacuna y de su profilaxis ${ }^{28}$. El artículo 12 disponía que los «académicos que componen el

26 Ibidem.

27 Ibidem.

28 El artículo 5 señalaba que las comisiones eran: «una especialmente consagrada al estudio patológico de las viruelas y de las diferentes erupciones varioliformes, así en la especie humana como en varias del reino animal, con el fin de fijar sus analogías y sus diferencias, determinar su origen, indagar sus filaciones, y llegar a un cabal conocimiento de sus mutuas sustituciones y de sus preservaciones recíprocas. Otra dedicada al estudio de la vacuna en toda su estensión, principalmente a la indagación de sus fuentes u orígenes, de sus resultados preservativos, de las degeneraciones y alteraciones que pueda sufrir, de las enfermedades transmisibles al inocular el virus vacuno, de los caracteres que con seguridad mayor distinguen la legítima erupción vacuna de la falsa, y de la virtud profiláctica relativa de los diferentes virus. Y otra, en fin, que estudie los adelantamientos y progresos que en otros países se hagan respecto a la profilaxis de las viruelas; que indague y proponga los mejores medios de adquirir y conservar virus vacuno de las procedencias que inspiren mayor confianza (...)», «Folletín. Un documento. Proyecto de Reglamento del Instituto Nacional de Vacunación», El Siglo Médico, 8-II-1874, no 1050, Ibid, p. 82. 
Instituto Nacional de Vacunación, disfrutarán como leve indemnización de sus tareas y pérdida de tiempo, de especiales derechos de asistencia que determinará la Academia.». Esta preocupación por las dietas constrastaba con la vaga referencia a la plantilla del organismo:

«Auxiliarán al Instituto en sus tareas dos o más médicos vacunadores, los ayudantes de vacunador que sean necesarios, y uno o más escribientes. Tendrá además para su servicio un conserje y los ordenanzas y mozos que necesiten ${ }^{29}$.

Los objetivos científicos, recogidos en el prolijo artículo 13, reflejaban todas las preocupaciones en torno a la vacuna que ya habían aflorado en el Discurso acerca de la preservación de las viruelas. Así, el estudio de la viruela como enfermedad; la obtención y conservación de vacuna; la evolución del virus de la misma; los factores que influían en la mengua de su acción; la transmisión o no de enfermedades por medio de la vacuna, y la mejor acción de la misma según su origen, eran cuestiones de especial interés. También se contemplaba la creación de estadísticas de vacunados y revacunados que reflejaran el tipo de virus utilizado y su grado de éxito. Por otra parte, los artículos 15 al 20 contemplaban que la principal actividad del Instituto debía ser el cultivo y distribución del virus, ahondando en abundantes detalles sobre la manera de obtenerlo ${ }^{30}$.

En el plano administrativo, se establecían dos niveles organizativos: las relaciones del Instituto con el gobierno y la Academia de Medicina y, la organización provincial y local de la vacunación. Por lo que se refiere al primer aspecto, el Instituto debía satisfacer las demandas de los ministerios de Fomento y Gobernación en el campo de la lucha antivariólica, así como proponer las medidas que considerase oportunas para el buen desarrollo de la misma. En cuanto al segundo punto, se plasmaba en la definición de la red de instituciones y funcionarios locales que debían cooperar con el Instituto. Desde los gobernadores civiles hasta los médicos y cirujanos de la Beneficencia municipal estaban involucrados en dicha tarea, ${ }^{31}$ instaurándose un sistema de

29 «Folletin. Un Documento. Proyecto de Reglamento del Instituto Nacional de Vacunación», El Siglo Médico, no 1050, 8 de febrero de 1874, p. 81-83.

30 «Proyecto de Reglamento del Instituto Nacional de Vacunación», El Siglo Médico, 8II-1874, nº 1050 , pp. 83-84.

31 El artículo 35 señalaba que los gobernadores civiles, Diputaciones provinciales, Juntas provinciales de sanidad, secciones de Fomento, subdelegados de sanidad, médicos, veterinarios, Alcaldes, Ayuntamientos, Juntas municipales de sanidad, médicos y cirujanos de la Beneficencia provincial y municipal, así como los veterinarios contratados por los municipios y 
vacunación aparentemente jerarquizado pero enormemente disperso, débil y descentralizado. Las Juntas provinciales de Sanidad, eran el principal elemento y se constituían en delegaciones del Instituto, teniendo «bajo su dependencia a los Subdelegados médicos y veterinarios de Sanidad, y también a los facultativos de la Beneficencia provincial y municipal, en lo que se refiere» al servicio de vacunación ${ }^{32}$.

\subsection{El conflicto con el Instituto Médico Valenciano.}

El conflicto entre la Academia y el Ministerio de Fomento no fue el único que generó la creación del Instituto Nacional de Vacunación. El Instituto Médico Valenciano también tuvo importantes desavenencias con el Ministerio de Fomento. Como señala Maria José Baguena en otro trabajo de este dossier, el Instituto Médico Valenciano se sintió dolido con el decreto del 24 de julio de 1871 porque en su preámbulo no se reconocía su labor en pro de la vacunación y en cambio se mencionaban experiencias de otros paises ${ }^{33}$.

Durante años el Instituto Médico Valenciano había colaborado con las instituciones del Estado suministrándolas vacuna y, convirtiéndose en un organismo de referencia nacional en los temas de vacunación. Por tanto, la omisión de su papel en el decreto no fue un lamentable olvido sino un acto intencionado que, al igual que el silencio ministerial ante el proyecto de la Academia de Medicina de crear un Centro de Vacunación propio, formaba parte de una misma estrategia consistente en intentar imponer como única institución legítimada para producir, distribuir y vacunar al Instituto estatal.

Las desavenencias entre ambos organismos no acabaron ahí. En la memoria de actividades del primer semestre de 1876 del Centro General de Vacunación — que era la nueva denominación del refundado Instituto Nacional de Vacunación-, su director Méndez Alvaro cuestionaba tanto la calidad de la vacuna del Instituto Médico Valenciano como la veracidad de los datos estadísticos de su actividad remitidos al Ministerio de Gobernación ${ }^{34}$.

los inspectores de carnes auxiliarián al Instituto en sus tareas en todas las provincias del reino. «Folletín. Proyecto de Reglamento del Instituto Nacional de Vacunación.» El Siglo Médico, 22 de febrero de 1874, $\mathrm{n}^{\circ}$ 1052, pp. 114-115.

32 Ibid, p. 115.

33 «Reflexiones que sujiere al Insitituto Médico-Valenciano el préambulo del Decreto del Ministerio de Fomento creando el un Instituto Nacional de Vacuna». Boletín del Instituto Médico-Valenciano, tomo XII, 1871, pp. 249-264.

34 Memoria (1876), pp. 20-22. 
La historia de la vacunación en la España del último cuarto del siglo XIX estuvo marcada por las pugnas institucionales y profesionales por hacerse con el mercado y el prestigio en este campo, y el Instituto estatal no fue ajeno a este género de conflictos. ${ }^{35}$

Todo el tortuoso proceso de creación del nuevo centro estatal y su ulterior desarrollo, estuvo vinculado al intento de constituir y controlar una nueva especialidad médica: la vacunología. Desde luego que el Instituto Nacional no fue la única entidad vacunadora que invirtió importantes esfuerzos en esta dirección. Prácticamente todas los institutos de vacunación privados reivindicaron esta práctica como una especialidad, lo que, por otra parte contribuyó a acrecentar tanto la pugna mercantil como la profesional entre entidades y médicos vacunadores. No se puede descuidar en este proceso las luchas entre personalidades, ni siquiera considerarlas un epifenómeno derivado de los otros conflictos. Por el contrario, estas formaron parte importante de las rivalidades apuntadas ${ }^{36}$.

\section{LA EXPERIENCIA VACUNADORA DE LA PRIMERA REPÚBLICA.}

\subsection{La orden-circular del 30 diciembre de 1873.}

Transcurrido un año y medio desde el Real Decreto de 24 de julio de 1871, el Instituto Nacional de Vacunación, no había comenzado a funcionar. La falta de presupuesto y el hecho de que emanara de un Ministerio que «no tenía la salud pública a su cargo» fueron las principales causas de su inactividad según apuntaron los coetáneos ${ }^{37}$. En todo caso, la escasez económica parece haber marcado al Instituto desde su fundación. Ya en las consideraciones generales al Reglamento se subrayaba que una de las dificultades con las que tropezaba el centro era la falta de presupuesto. De hecho, se señalaba que se procuraba articular un Reglamento que estuviera en concordancia con la realidad del erario público, sacrificando un desarrollo más ambicioso:

«Otra advertencia se permitirá para concluir: al trazar la organización que su concepto debe darse al Instituto, no ha podido desentenderse de la necesidad, temporal al menos, de reducir cuanto sea posible los nuevos gastos que habrán de gra-

\footnotetext{
35 CAMPOS (2001).

36 Ibid.

37 Memoria (1876), p. 7.
} 
var el presupuesto para establecerle. La magnitud del pensamiento del gobierno en el Real Decreto de 24 de julio último esplanado, y la consideración de que realizándole puede reportar a la nación inmensos beneficios, exigían ciertamente una organización más amplia, y para ello gastos de más consideración; pero ha tenido por preferible aquello que con facilidad mayor puede realizarse ${ }^{38}$.

Los acontecimientos políticos del país también tuvieron su incidencia en la falta de impulso para sacar adelante la institución. Sin embargo, la pervivencia de las epidemias de viruela fue un elemento que aguijoneó a los diferentes régimenes políticos a intentar su puesta en marcha. En cierto modo, entre 1871-1876 se produjo una paradoja: existía, al menos en apariencia, una voluntad política, que prevalecía por encima de la propia lucha política, de crear un organismo de vacunación estatal estable que, sin embargo, encontró enormes dificultades de desarrollo debido a la falta de empuje definitivo por parte de la administración, que nunca dotó al Instituto con la plantilla y el presupuesto adecuado.

El gobierno republicano, también intentó impulsar la vacunación por medio de la Orden-circular del 30 de diciembre de 1873 que dictaba diversas medidas encaminadas a combatir la epidemia variolosa que afectaba a varias poblaciones españolas. La primera fue encargar a los representantes diplomáticos en Nápoles y París la compra de 100 tubos de linfa vacuna en los institutos de vacunación de dichas ciudades ${ }^{39}$. Además desde la capital francesa debían remitirse a Madrid «tres terneras inoculadas, con destino a la escuela de Veterinaria para la conservación y propagación de la vacuna en otros animales ${ }^{40}$. Junto a estas medidas se determinaba que se hiciera obligatoria la vacunación y revacunación de la población asilada, reclusa, escolar y mili$\operatorname{tar}^{41}$. También se incitaba a las autoridades e instituciones provinciales y mu-

38 ARAMM, Leg 107, Doc 4723 (III).

39 «Decreto», El Siglo Médico, 4 -I-1874, n 1054, p. 14.

40 Ibidem.

$41 \ll 3^{\circ}$ Que se haga obligatoria la vacunación y revacunación de cuantas personas estén bajo la inmediata dependencia de las autoridades civiles en Hospicios, Colegios o establecimientos Penales, etc., y aun en los hospitales, debiendo los enfermos ser vacunados a su entrada, si a ello no se opone su dolencia, a juicio del facultativo.

$4^{\circ}$ que en los Hospitales se disponga la inmediata separación de todo varioloso, estableciendo para esta enfermedad, caso necesario, locales alejados en lo posible del resto de la población.

$5^{\circ}$ Que por los ministerios de Guerra y Marina se adopten las disposiciones convenientes para que sin excusa alguna sean escrupulosamente vacunados o revacunados todos los individuos del ejército y armada, aun los que se hallen en funciones de guerra, puesto que las pequeñas incomodidades de la operación no les invalidan para aquellas; adoptándose para la 
nicipales a extender la vacunación «ya imponiendo la obligación de vacunar y revacunar a cuantos de ellas dependan, ya excitando el interés particular, ya destruyendo errores y preocupaciones vulgares» ${ }^{42}$.

Finalmente ante la escasez de vacuna en el territorio nacional el gobierno encargaba a los establecimientos y autoridades locales la tarea de proveerse de linfa para poder proceder a la vacunación con garantías de éxito:

«El Gobierno trata por cuantos medios están en su mano de conseguir cantidad suficiente del mejor pus vacuno con que atender a las necesidades de este servicio; pero en tanto se realizan sus deseos, y sin perjuicio de contribuir por su parte con los elementos de que hoy dispone, abriga la esperanza de que todas las autoridades y coorporaciones a quienes toca cumplir esta disposición apurarán los recursos que estén a su alcance para adquirir de su cuenta la más eficaz linfa vacuna, bien de los establecimientos que se dejan citados, bien del Instituto Médico Valenciano, señalados por su reputación, o de los puntos que juzguen más convenientes» ${ }^{43}$.

La orden republicana se caracterizaba por su tono liberal y por la preocupación ante la falta de vacuna para cubrir las necesidades de la población. En este sentido, las disposiciones gubernamentales resultaban escasamente intervencionistas, limitándose a recomendar la vacunación y revacunación de la población. Sólo los individuos tutelados por el estado eran objeto de disposiciones más autoritarias. Además en concordancia con esta línea liberal, el gobierno, una vez más, delegaba en las instituciones provinciales y locales buena parte de su responsabilidad en la obtención y distribución de la vacuna. En cierto modo el gobierno republicano daba un paso atrás sobre la tímida actitud del gobierno monárquico, pues ni siquiera mostraba la intención de impulsar un organismo estatal que coordinase la vacunación. En cualquier caso, ni uno ni otro llegaron a plantear la posibilidad de promulgar una ley de vacunación obligatoria. Lejos de ello, se limitaron a recomendar la extensión de la vacunación.

En cuanto a los problemas de suministro de vacuna, se pretendía paliar la dependencia exterior, importando vacuna animal para cultivarla en España. La novedad por tanto, residía en el cambio de técnica de obtención y aplicación de la vacuna.

hospitalidad militar y terrestre y marítima iguales disposiciones a las consignadas en la resolución anterior». Ibidem.

42 Ibidem.

43 Ibidem 


\subsection{La introducción de la vacuna animal en España. El polémico caso del} Dr. Lanoix.

Disuelta la Asamblea republicana por el golpe del general Pavía, el nuevo gobierno republicano presidencialista de $\mathrm{Serrano}^{44}$ retomó la cuestión de la vacunación por medio de una circular de la Dirección General de Beneficencia y Sanidad dirigida a los gobernadores civiles, fechada el 7 de febrero de $1874^{45}$. Tras la habitual retórica sobre los deberes del Estado ante las epidemias, se confirmaba la recepción de los 100 tubos y las terneras vacuníferas solicitadas en cumplimiento de la Orden circular del 30 de diciembre.

También se notificaba que el Dr. Lanoix ${ }^{46}$, director del Instituto de Vacunación de París, «movido por sentimientos filantrópicos», había viajado voluntariamente a Madrid con el objeto de acompañar y cuidar a las reses y «enseñar su método a los facultativos españoles», conducta que los responsables de la circular encomiaban ${ }^{47}$.

Aprovechando la presencia del médico francés en Madrid y previa consulta con el Consejo de Sanidad, la Dirección general de Beneficencia y Sanidad, nombró una Comisión provisional honorífica formada por ocho médi$\cos ^{48}$ con el objeto:

44 La Primera República se instauró el 11 de febrero de 1873. La disolución de la Asamblea nacional por el general Pavía en la noche del 2 al 3 de enero de 1874 no significó la desaparación de dicho régimen sino un giro del mismo en el que la orientación política tomó derroteros presidencialistas y conservadores. Martínez Cuadrado ha calificado este período como segunda etapa republicana y se caracterizó por «el repliegue hacia posiciones conservadoras de hasta entonces burguesía radical.» MARTínEZ CUADRADO, M. (1983), La burguesía conservadora (1874-1931), Madrid, Alianza Universidad, pp. 7-11.

45 «Circular», El Siglo Médico, 15-II-1874, n 1057, p. 109.

46 Sobre la figura de Lanoix existe abundante información en el trabajo de MLLE LANOIX, (1928), «Une page d'Histoire de la vaccine», Paris Médical, no 48, pp. 437-450. En dicho trabajo se da una versión de su viaje a Madrid bastante edulcorada y contradictoria con la de El Siglo Médico, afirmándose que fue llamado por el gobierno español y que fue nombrado miembro de la Academia de Medicina. También se señala que 22 profesores españoles firmaron un testimonio de confraternización y gratitud por sus trabajos en España y la tarea de propagación de la vacuna animal. Vid p. 447.

47 «Circular», El Siglo Médico, 15-II-1874, n 1057, p. 109.

48 La comisión en cuestión estaba compuesta por « D.Bonifacio Montejo, Presidente; e individuos de la misma D. Joaquín Badals, visitador general de Beneficencia y Sanidad; D Gregorio Sánchez Beato, D. Luis Felipe García, D. Antonio Espina y Capo; y de dos profesores designados por el ministerio de la Guerra y uno por el de Marina que han sido los Sres, D. Joaquín Pla Y Pujol, D. Gabriel Ramón Adrover y D. Luis Alvarez Zarza», Ibidem. 
«de presenciar las operaciones vacunadoras de Mr. Lanoix, en las que aquella ha tomado parte bajo la dirección de tan distinguido profesor, inoculando en otras el fluido de las indicadas terneras; conservar y trasmitir sucesivamente el virus vacuno en la especie bovina a fin de mantener perenne el manantial de la vacunación; preparar tubos para remitirlos a provincias, y cuanto con este servicio requiere la acción científica en sus operaciones prácticas»» ${ }^{49}$.

El interés por importar vacuna animal respondía a la necesidad de garantizar tanto la existencia de reservas suficientes de fluido vacuno como las condiciones higiénicas de la vacunación. Tradicionalmente en España se utilizaba la vacuna jenneriana o de brazo. Este tipo de vacuna, ante la inexistencia del cow-pox original en nuestro país, normalmente se importaba de Londres, pero su eficacía a comienzos de la década de 1870 estaba en entredicho. Dos problemas de díficil solución se le atribuían: su degeneración y consiguiente pérdida de eficacia por el constante paso de brazo en brazo y su asociación con la transmisión de diversas enfermedades, especialmente la sífilis. Ambos incovenientes fueron negados por los partidarios de la vacunación y utilizados como argumento de peso por sus detractores. La experiencia fue dulcificando la posición de los primeros, que terminaron por admitir la pérdida de eficacia de la vacuna y la transmisión de enfermedades en determinadas circunstancias. Ahora bien, la mayoría de los autores consideraban que ambos fenómenos se debían al desconocimiento de las técnicas de vacunación y al uso incorrecto del fluido. Con todo, la opinión favorable a introducir la vacuna animal fue ensanchándose en el periodo estudiado..$^{50}$

Su origen se remonta a 1804, cuando en Nápoles Troja y Galbiati abandonaron la vacunación de brazo a brazo al constatar la existencia de sífilis vacunal. En años sucesivos la técnica se iría perfeccionando hasta que en 1840 Negri popularizó y mejoró el cultivo en las terneras. En 1864 en el Congrès médical international de Lyon se propuso el abandono definitivo de la linfa humana en favor de la vacuna animal. Los doctores Chambon y Lanoix recogieron el mensaje y tras un viaje del último a Nápoles donde se ilustró sobre

49 Ibidem. Por lo demás la circular se mostraba muy autocomplaciente tras las experiencias referidas pues el Gobierno había conseguido su principal objetivo: la obtención y conservación de linfa vacuna suficiente para vacunar a la población. Recordaba asímismo, a los gobernadores que excitasen el patriotismo y los sentimientos humanitarios de las Diputaciones, Ayuntamientos y Juntas provinciales y locales de sanidad para que organizasen institutos de vacunación locales, instándoles también a elaborar estadísticas quincenales.

50 CAMPOS MARÍN (2001), pp. 9-13 
la técnica de la vacunación animal, regresó a París con una ternera inoculada, introduciendo así la nueva modalidad de vacuna en Francia ${ }^{51}$.

Las críticas a la presencia de Lanoix en Madrid no se hicieron esperar. Frente al tono complaciente de la Dirección General de Beneficencia y Sanidad, surgieron voces que matizaban e incluso impugnaban la necesidad de dicho viaje. Las primeras valoraciones de El Siglo Médico sobre el asunto tuvieron un tono contenido, pues aunque mostraban su desacuerdo con la manera de proceder de las autoridades sanitarias, se reconocían los aspectos positivos y benefactores de los experimentos de Lanoix. Si bien, el editorialista, se encargaba de señalar que aquel no aportaba «ideas nuevas acerca de su especialidad», ni describía «métodos desconocidos para llevar a cabo la vacunación» ${ }^{52}$.

No obstante, en abril de 1874, El Siglo Médico publicó una extensa carta de Gerónimo Roure, en la que recordaba que en Vitoria se vacunaba bajo su dirección con linfa animal proveniente del Instituto práctico de vacunación animal de Cuba y Puerto Rico a cuyo cargo estaba el Dr. Luis Vicente Fe$\operatorname{rrer}^{53}$. De paso recordaba que dicha técnica también había sido introducida en España por el Dr. Letamendi. Por ello, mostraba su sorpresa e indignación por los apoyos que Lanoix recibía del Consejo Superior de Sanidad y de la Dirección General de Beneficencia y Sanidad, considerándolos un agravio hacia los médicos españoles

\begin{abstract}
«Ocúrrenos sin embargo que en el modo de realizarla tal vez hubiese podido proceder con más tino, adquiriendo previa y oportunamente los datos necesarios para averiguar el estado de la vacunación en España; lo cual quizá le hubiese ahorrado dispendios y demandas de favores a los extraños, que estos han podido interpretar en poco favorable sentido para la clase médica de nuestro pais.(...) Porque el hecho es que habiéndose podido llevar a cabo la reforma de que hemos hecho mérito sin apelar a recursos extraños y utilizando los existentes en nuestro país, hemos ido a mendigarlos al extranjero sin necesidad de ello, dando así lugar a que se nos juzgue más atrasados de lo que estamos y se crea necesaria entre nosotros la pre-
\end{abstract}

51 Sobre la introducción de la vacuna animal en Francia y su desarrollo véase DARMON, P. (1986), La lonque traque de la variole, Paris, Perrin, pp. 350-371; también son de interés FAsQuelle, A (1932), Ernest Chambon (1836-1910), Paris, y PonTECorvo, M. (1991), Storia delle vaccinazioni, dalle origini ai nostri giorni, Roma.

52 Las posiciones de El Siglo Médico, defendidas por J. Cortezo bajo el seudónimo de Decio Carlán, están reflejadas en «Revista de la Semana. Una conferencia en francés» y en «Revista de la Semana. Más sobre la vacunación» El Siglo Médico, 15-II-1874, n 1051, p. 97 y 22-II-1874, $\mathrm{n}^{\mathrm{o}} 1052$, pp. 113-114.

53 «Variedades. La vacuna animal en España», El Siglo Médico, 26-IV-1874, n 1061 , pp. 262-264. 
sencia de un preceptor que venga, no sólo, según tiene derecho a creer el Sr. Lanoix, a revelarnos una invención de que sólo teniamos vagas noticias, sino a instruirnos en los detalles más minuciosos del procedimiento de vacunación directa, que sólo por desconfianza de nuestra pericia, se comprende que dicho señor, sin invitación directa para ello, se decidiera a acompañar a sus terneras en el viaje y a enseñar su método a los facultativos españoles, conducta que la Dirección de Beneficencia y Sanidad ha visto con la mayor satisfacción, según expresa en su circular de 7 de Febrero» ${ }^{54}$.

Las vacunaciones, practicadas por Roure, aunque sólo afectaron a 148 individuos tuvieron un elevadísimo éxito y fueron el origen de la creación en 1875 del Centro de vacunación y revacunación animal de la provincia de Alava y de Vitoria ${ }^{55}$.

El trasfondo de ésta actitud, compartida por El Siglo Médico, residía en una mal disimulada reacción nacionalista que se concretaba en dos aspectos estrechamente ligados: el sentimiento de desprecio hacia la ciencia española que suponía la estancia de Lanoix en la capital y, la reivindicación de algunos médicos españoles de experiencias semejantes realizadas en España con anterioridad a la importación de las terneras francesas. Como complemento de esta actitud, se sumaría una cierta «fiebre» por crear institutos de vacunación animal o por demostrar la «paternidad» de su introducción en nuestro país. En cualquier caso y con independencia de la polémica generada, la vacuna animal que Lanoix dejó en Madrid, marcó profundamente el futuro inmediato de los sucesivos organismos estatales de vacunación.

3.3. La confusa paternidad de la introducción de la vacuna animal en España.

La crítica de Roure tenía un fondo de razón. La vacunación animal no era desconocida en España y existían varios intentos de implantarla con anterioridad a la visita de Lanoix. Méndez Alvaro, en su Discurso de 1871 había resumido los conocimientos existentes sobre la misma. En febrero de 1872, tras el fracaso del Instituto Nacional de Vacuna, el Dr. Ferrer envió a la Aca-

54 Ibid., p. 264

55 Sobre este Centro, cuyo máximo inspirador fue el Dr. Roure véase APRAIZ y SAENZ DEL Burgo, R. (1896), Primer centenario del descubrimiento de la vacuna por Jenner. Discurso pronunciado en la Sesión conmemorativa de dicho Centenario celebrada el día 14 de mayo de 1896 en el Salón de actos públicos del Instituto provincial por el Centro de vacunación animal de Álava y el Ateneo de Vitoria por el Director facultativo de dicho Centro y ex-Presidente del Ateneo Dr. D ..., Vitoria, Establecimiento Tipográfico de Domingo Sar, pp. 99- 119. 
demia de Medicina una relación de pústulas vacunas para que se procediera a vacunar con ellas ${ }^{56}$. A raiz de este envío el 9 de abril, la Academia solicitó al Ministerio de Fomento permiso para la creación de un Instituto de Vacunación Animal. Asimismo, pidió al Alcalde de Madrid autorización para coordinarse con los facultativos del cuarto distrito, por ser los más próximos a la Escuela de Veterinaria, lugar donde se pensaba establecer «el centro de vacunación animal» ${ }^{57}$, obteniendo el beneplácito del consistorio cuatro días más $\operatorname{tarde}^{58}$. Por su parte, el Ministerio de Fomento comunicó el 6 de junio a la Academia que ante la inexistencia de «partida alguna en el presupuesto vigente de este Ministerio» para atender a los gastos de los «experimentos de la vacunación animal», se había decidido «coadyuvar a tan laudables fines» con la cantidad "que para material ordinario tiene consignadas» ${ }^{59}$ La Academia procedió a inocular dos terneras con la linfa enviada por Ferrer, en colaboración con los facultativos municipales, aunque sin resultados positivos por lo que esta técnica fue abandonada hasta 187460 .

También en 1872, J. Letamendi, J. Giné y Partagás y A. Anet fundaron la Sociedad Barcelonesa para la vacunación animal que, a juzgar por los testimonios de Roure y de Méndez Alvaro, sería la primera institución que prácticó la vacuna animal en España ${ }^{61}$. Por su parte, el mencionado Anet en 1878 firmó una

56 ARAMM, Legajo 109. Doc 4779.

57 ARAMM. Legajo 105. Doc 4692 (I).

58 ARAMM. Legajo 109. Doc 4781.

59 ARAMM. Legajo 109. Doc 4783.

60 La Academia compró dos terneras que le costaron 520 pts para proceder a su inoculación con la linfa cubana. ARAMM. Legajo 109. Doc, 4782. La mencionada carta de Roure a El Siglo Médico iba precedida de un comentario en el que se señalaba que la Academia de Medicina había recibido la vacuna del Dr. Ferrer para que «fuera inoculado, así en terneras como en nuestra especie. La Academia adquirió terneras y encomendó la vacunación, en ellas y en el hombre, a los profesores de la Casa de Socorro de Beneficencia municipal de uno de los distritos, obteniendo al efecto la correspondiente orden del alcalde municipal. Bajo la inspección del director de la escuela de Veterinaria, académico e individuo de la comisión de vacunación de aquel cuerpo científico se hicieron muchas inoculaciones con tan mala suerte que ningun resultado logró obtenerse». «La vacuna animal en España», El Siglo Médico, 26-IV-1874, n 1061, p. 262.

61 El dato de la fundación puede verse en APRAIZ (1896), p. 24; la introducción de la vacunación animal atribuida a Letamendi puede verse en la citada carta de Roure a El Siglo Médico y en la Memoria (1876), p. 8. Más información sobre esta Sociedad puede verse en Ausin Hervella, J.L. (2003), Dr. Giné i Partagàs (1836-1903). En homenatge. Giné i Partagàs, impulsor de la modernització de la medicina catalana, Barcelona, Collegi Oficial de Metges de Barcelona, pp. 147-149. 
memoria en la que se atribuía la introducción en España de dicho tipo de vacuna, si bien no especificaba la fecha en que había comenzado a inocularla ${ }^{62}$.

J.M $M^{a}$ Esquerdo también se interesó por esta técnica de vacunación, presentando a comienzos de 1874 ante la Academia un proyecto de Instituto Libre de Vacunación, que tenía claramente el objetivo de constituirse en centro productor y proveedor de vacuna de las instituciones estatales. Así, proponía mantener "constantemente vacuna fresca en la especie bovina,» vacunar y revacunar gratuitamente a los acogidos en la Beneficencia general, regalar 1000 cristales de vacuna anualmente, así como cubrir los pedidos que hiciera el Ministerio de Gobernación al precio que este designase. Como contrapartida proponía que el Estado le cediese durante al menos diez años «la casa denominada de vacas y los terrenos comprendidos en el cuartel que lleva su nombre», con el objeto de mantener el ganado necesario para el fomento de la vacuna. Proponía además que todas las operaciones realizadas por su Instituto fueran sometidas a la inspección de un «Consejo constituido por un individuo del Consejo de Sanidad de la nación, un individuo de la Academia nacional de Medicina y Cirugía, el decano de la Facultad de Medicina, y el director de la Escuela especial de Veterinaria» ${ }^{63}$.

Ante las acusaciones de oportunismo, Esquerdo se defendía señalando que su interés por la vacuna era añejo, y que sus experimentos contaban con el visto bueno del Dr. Lanoix de visita en Madrid ${ }^{64}$.

62 DR. ANET (1878), De la viruela y su profilaxis por el Dr... Introductor y propagador de la vacunación animal en España. Memoria leida en la Academia Médico-Farmacéutica de Barcelona dando cuenta de los trabajos de la Comisión permanente de vacunación de la misma, Barcelona, Establecimiento Tipográfico de José Miret. Según APRAIZ (1896), p. 24, el Dr. Anet dirigía el Establecimiento Barcelonés para la vacunación con linfa de vaca (cowpox), aunque sin señalar su fecha de creación.

63 EsQuerdo, J.M. «Instituto Libre de Vacunación», El Siglo Médico, 29-III-1874, n 1057 , p. 206.

64 Las palabras textuales de Esquerdo son: «Podrá este proyecto ser bueno o malo: dispuesto estoy a defenderle, que yo jamás rehuí discusión ni polémica alguna; pero fuere como fuere, creo no merecer que se me aplique lo de «que afición va entrando a la vacuna», por cuanto mi afición es ya añeja» Ibidem. Por otra parte, en la biografía de Esquerdo que escribió Eleizegui, se reproduce el proyecto de su instituto de vacunación, y se dice de manera confusa y claramente apologética: «Por eso, haciendo alarde de sus doctrinas, lleva a su cátedra la ciencia nueva, y en su sala del Hospital recoge cuanto adelanto y progreso a él llega. Apenas empieza a hablarse en el extranjero de la vacuna de la viruela, eran poco conocidos aún los admirables trabajos de Jenner, y ya Esquerdo tiene para su servicio del Hospital tres terneras vacunadas, que el mismo hizo venir de París. Por cierto que cuando hacía ya tiempo que Esquerdo enseñaba a sus alumnos práctica y experimental, todos los detalles del nuevo método preventivo, en la Academia Médi- 
El interés mostrado por los médicos y la administración española hacia la vacunación animal tuvo, no obstante, resultados muy irregulares. En los años siguientes se fundaron diversos institutos de vacunación públicos o privados ${ }^{65}$ que utilizaban como reclamo la vacuna animal, si bien también existieron otros, como el Instituto Médico Valenciano que mantuvo la vacunación de brazo durante mucho tiempo. Por lo que respecta a los experimentos potenciados por la administración en 1874 estos marcaron profundamente el devenir de los intentos estatales por poner en funcionamiento un centro de vacunación entre 1875-1877.

\section{UN TERCER INTENTO: LA DIFICULTOSA CONSOLIDACIÓN DEL INSTITUTO DE VACUNACIÓN DEL ESTADO DURANTE LA RESTAURACIÓN (1875-1877).}

\subsection{5: la creación del Centro provisional de vacunación.}

El cambio de régimen político operado a finales de diciembre de 1874, con la Restauración de la monarquía borbónica, trajo aparejado en el terreno de la lucha contra la viruela un nuevo esfuerzo por fundar un organismo estatal de vacunación ${ }^{66}$. El fracaso del ensayo republicano de cultivar y distribuir vacu-

co-Quirurgica seguía debatiéndose el tema con soporífera o inacabable discusión exclusivamente teórica. Una prueba más de la utilidad manifiesta que por la cultura del país tienen las Sociedades cuando cultivan ciencia de oropel». EleIZEguI, J. (1914), Don José Ma Esquerdo, Madrid, Imprenta de Antonio Marzo, p. 24; Sobre el apoyo de Lanoix: J.M. Esquerdo, «Instituto Libre de Vacunación», El Siglo Médico, 29-III-1874, n 1057, p. 206.

65 La proliferación de centros privados de vacunación fue favorecida la Real Orden de 14 diciembre de 1872 que consagró el libre mercado vacunífero al disponer que los médicos no necesitaban la autorización del Gobierno para establecer Institutos de vacunación por ser «industria libre y lícita para los Profesores de la ciencia de curar». DIRECCIÓN GENERAL DE SANIDAD (1903), p. 78.

66 Aunque en ninguna de las dos circulares republicanas (30-XII-1873 y 7-II-1874), se contemplaba la creación de un Instituto de vacunación, sino exclusivamente la obtención, distribución y conservación de vacuna animal, es probable que implícitamente se estuviera pensando, con dichas medidas, en activar el Instituto fundado por Ruiz Zorrilla. Según se cuenta en la exposición de motivos de la Real Orden de 17 de abril de 1875, por la que se creaba un Centro provisional de vacunación, el 7 de marzo de 1874 había quedado instalado en la Escuela de Veterinaria de Madrid «bajo la autoridad inmediata de una Comisión provisional honorífica, compuesta de ocho profesores de la Facultad de Medicina», un Instituto de Vacunación, con el encargo de «proseguir las operaciones vacunadoras de Mr. Lanoix, dirigir y estudiar las vacunaciones y revacunaciones, ordenar la colocación de la linfa preservativa en 
na animal en el territorio nacional, movió al nuevo gobierno a crear el 17 de abril de 1875 un Centro de vacunación «sobre fundamentos más sólidos que los preferidos en su creación, imprimiendo a los servicios la tendencia, orden y regularidad que demandan las difíciles e interesantes cuestiones de higiene pública que el Gobierno se propone esclarecer» ${ }^{67}$.

Las fallidas experiencias anteriores alimentaban la cautela de los legisladores que optaron por la creación de un Centro provisional de vacunación, cuya continuidad estaría sujeta a los resultados que obtuviera en el plazo de un año. El diseño administrativo del mismo era nítidamente centralizador. El Centro quedaba bajo «la inspección y dirección inmediata de la Real Academia de Medicina», cuya Comisión de vacuna ejercería de «autoridad delegada del Gobierno en todo cuanto se relacione con la vigilancia, orden, servicio y prácticas dentro y fuera del establecimiento.» Además, esta vez si, se encargaba directamente a la Academia la redacción del reglamento del Centro. (Art.1).

La centralización iba acompañada del control gubernativo. El artículo $2^{\circ}$ encomendaba a un auxiliar médico de la sección de sanidad del ministerio de la Gobernación, el control y custodia de los libros y registros de vacunaciones y revacunaciones así como los referentes a los datos relacionados con el cultivo de la linfa. También se encargaría del seguimiento de la contabilidad del establecimiento ${ }^{68}$.

El resto del Decreto organizaba la plantilla y sus atribuciones. Esta, a todas luces insuficiente, se reducía a dos médicos vacunadores ${ }^{69}$ "con un sueldo anual de 1000 pesetas el primero y honorario el segundo»y, a cuatro practicantes alumnos de la Facultad de Medicina, que cobraban 250 pts cada uno. Tanto los médicos como los practicantes estaban sometidos a la disciplina del Presidente de la Comisión de Vacunación. La contratación de personal subalterno (mozos y dependientes) quedaba abierta a las necesidades del Centro. Asimismo, la Comisión estaba obligada a elevar «un resumen de sus experiencias y observaciones» y una estadística general de vacunaciones y revacunaciones con una periodicidad mensual en el primer caso y trimestral en el segundo. Los Gobernadores civiles debían remitir a la Comisión noticias sobre el valor profiláctico de la vacuna envíada desde $\mathrm{Madrid}^{70}$.

tubos para su envío a las provincias y disponer cuanto en este utilísimo servicio requiere la intervención científica.» «Parte Oficial. Ministerio de la Gobernación. Reales Órdenes», El Siglo Médico, 2 de mayo de 1875, n 1114, pp. 285-286.

67 Ibid., p. 285.

68 Ibidem.

69 Ibidem.

70 Ibidem. 
La actividad del Centro durante 1875, resumida en el informe que presentó su director Gabriel Usera, estuvo marcada por las dificultades para obtener vacuna animal de buena calidad, vacunar a la población y recoger estadísticas precisas sobre dicho proceso. ${ }^{71} \mathrm{La}$ falta de datos y de informes veraces sobre la actividad vacunadora, durante el periodo republicano y las trabas que pusieron sus responsables para facilitarselas a los nuevos gestores, fueron el primer problema con el que tropezó el Instituto ${ }^{72}$. Sin datos verídicos en los que apoyarse el Centro provisional comenzó a funcionar procurando conservar la vacuna que había importado el Dr. Lanoix y que, según vagos informes, todavía permanecía en una ternera. Se procedió a inocular la misma linfa a otra ternera, obteniendo resultados positivos al reproducirse pústulas semejantes a las de la primera. Sin embargo, su aplicación al ser humano entre abril y julio fue un fracaso. ${ }^{73}$ Tras la suspensión de la vacunación en agosto, se retomó en septiembre con linfa «procedente de las costras remitidas por el Sr. Roure», vacunándose a 124 personas, de las cuales prendieron sólo en 45.

Los negativos resultados de las vacunaciones, llevaron a los miembros de la Comisión de Vacunación de la Academia a inocular viruela benigna a dos terneras con la esperanza de que ésta se transformase en vacuna ${ }^{74}$. En una de

71 La información sobre las labores desempeñadas por el Instituto durante el año $1875 \mathrm{se}$ encuentran en el Informe que el Presidente de la Comisión de vacunación de la Academia de Medicina, elevó al Ministerio de la Gobernación. No hemos localizado ningún ejemplar impreso del mismo, utilizando el manuscrito que se encuentra en la Real Academia de Medicina de Madrid: ARAMM. Legajo 140. Documento 7024.

72 Se solicitaron informes al Presidente de dicha comisión, Bonifacio Montejo, sobre los resultados de las vacunaciones y revacunaciones realizadas bajo su dirección, a la que contestó verbalmente, ofreciendo datos muy positivos exclusivamente del ejército, lo que mereció las críticas de Usera: «Escasos consideró estos datos la Comisión por ser solo de referencia, no haber sido escritos y menos apoyados en diario alguno de observaciones, por lo cual determinó empezar estos y los otros ensayos con que hubiera y como pudiera». Las excusas y dificultades alegadas por Montejo para transmitir la información a los dirigentes del nuevo Instituto, bien pudieron estar motivadas por el malestar de la disolución de la Comisión honorífica y la transferencia de sus competencias a la Academia de Medicina. ARAMM. Legajo 140. Doc. 7024.

73 En un principio se vacunó a 11 niños con pus de la primera ternera no obteniendo ningún resultado positivo. Más adelante, y tras sucesivos intentos de conservación de la vacuna, se vacunaron 24 niños en mayo prendiendo tan sólo en 3 , y en junio sobre 22 vacunados sólo hubo 5 operaciones positivas, para pasar en julio ninguna. ARAMM. Legajo 140. Doc. 7024.

74 «La comisión que abriga la duda como un medio de investigación que nota que si la viruela y la vacuna no son enfermedades idénticas, se sustituyen, teniendo certeza que la vacuna el Cow-pox preserva de la viruela y que el que ha sufrido esta sobre todo recientemente, se hace refractario a la vacuna; ha querido examinar si la viruela natural inoculada en la terne- 
ellas se formaron pústulas semejantes a las obtenidas por Lanoix y Roure, procediéndose a su cultivo con el objeto de consevarla y experimentar en el ser humano. Finalmente se vacunó a dos niños, que enfermaron de viruela y la Comisión decidió abandonar este tipo de experimentos:

«De la octava generación en las terneras se trasladó a dos niños pero el resultado [h] a sido el convencimiento que la viruela es viruela, y la vacuna es vacuna, que la viruela engendra viruela, la vacuna engendra vacuna.

En los dos niños prendieron, pero en los dos presentaron viruelas, que hemos podido observar en uno de ellos, pues respecto del otro su familia se negó a que fuese visto por los empleados en el Centro de Vacunación. De todos modos estos hechos positivos, y aunque no fuese mas que uno el que hemos podido inspeccionar por nosotros mismos, es suficiente para que se abandone esta clase de ensayos peligrosos para los que sirven de objeto de ellos ${ }^{75}$.

Esta experiencia muestra que los miembros de la Comisión desconocían las reflexiones de Méndez Alvaro sobre este asunto. El ilustre médico, basándose en la literatura científica del momento, señalaba en su Discurso la falta de identidad entre la viruela y la vacuna y advertía que la inoculación de viruelas a las vacas daba como resultado viruela ${ }^{76}$. La ignorancia de los responsables del Centro de vacunación era todavía más sorprendente porque estaban bajo el control de la Academia de Medicina, en cuyo seno Méndez Alvaro había publicado su obra.

Además de los problemas relacionados con la obtención de vacuna, el Centro provisional tuvo que enfrentarse con la escasez de vacunados tanto en Madrid como en el resto de las provincias. De hecho, las estadísticas que enviaban los Gobernadores civiles eran muy incompletas y no aclaraban el origen de la vacuna utilizada, con lo cual el Centro no disponía de los datos esenciales para controlar el proceso.

\subsection{La fundación definitiva del Instituto de Vacunación del Estado.}

A pesar de su deficiente funcionamiento, el gobierno por una Real Orden fechada el 24 de enero de 1876, dio al Centro carácter definitivo, pasando a

\footnotetext{
ra se animaliza y se convierte en verdadera vacuna pues si tal aconteciera tendriamos un medio de renovar la vacuna de un modo constante. Ibidem.

75 Ibidem.

76 Mendez Álvaro (1871), p. 27 y p. 43.
} 
denominarse Centro General de Vacunación. En líneas generales se mantenían las atribuciones contempladas en 1875, si bien la Comisión de Vacunación de la Academia de Medicina incrementaba ligeramente su poder y se proveía al Centro de mayores recursos y de una plantilla más nutrida y mejor paga$\mathrm{da}^{77}$. Esta última quedaba compuesta por un médico jefe, cuatro médicos vacunadores, cuatro prácticantes y tres mozos de los cuales uno tenía la función de conserje. El Siglo Médico ensalzó estas mejoras al hacer balance de sus primeros meses de funcionamiento. Para los redactores el Centro estaba bien organizado y llevaba a cabo sus tareas satisfactoriamente ${ }^{78}$. Sin embargo, una Real Orden del 1 de julio recortaba la plantilla «en virtud de las economías introducidas por las Cortes en los presupuestos generales del Estado», suprimiéndose los cuatro prácticantes, que ya no aparecían en el Reglamento remitido por la Academia de Medicina para regir su funcionamiento ${ }^{79}$. Compuesto por 21 artículos, regulaba tanto los aspectos científicos y como los organizativos e institucionales.

Sin embargo, la mejor organización y dotación económica y material no impidió que las anteriores dificultades lastrasen su funcionamiento en el nuevo periodo. El nuevo director, Francisco Méndez Alvaro, consideraba que el Centro disponia de los medios adecuados para llevar a cabo su labor con digni$\mathrm{dad}^{80}$, si bien reconocía que carecía de un pequeño establo con las «convenientes condiciones de salubridad y abrigo» para albergar las terneras necesarias. Además la adquisición de terneras que reunieran las condiciones sanitarias y

77 «Parte oficial. Ministerio de la Gobernación», El Siglo Médico, 20 de febrero de 1876, $\mathrm{n}^{\circ} 1156, \mathrm{p} .122$.

78 «Variedades. El Centro General de Vacunación.» El Siglo Médico 23 de julio de 1876 $\mathrm{n}^{\circ} 1178, \mathrm{p} .476$.

79 La Real Orden del 1 de julio puede consultarse en ARAMM Legajo 127. Documento 6036. En el Documento 6039 de dicho legajo se conserva una comunicación del Ministerio de Gobernación al Presidente de la Real Academia de Medicina fechada el 14 de julio de 1876 en la que se indica que el Rey ha aprobado el reglamento presentado por el Centro General de Vacunación, debiendo no obstante «ser eliminado su artículo 20 que trata del servicio de los Practicantes cuyo personal quedó suprimido al empezar el actual año economico». El Reglamento puede consultarse en «Dirección General de Beneficencia y Sanidad. Reglamento aprobado por Real Orden de 14 de septiembre del corriente año para el Centro general de Vacunación» El Siglo Médico, 23 de octubre de1876, n 1191, pp. 683-684.

80 Según Méndez Álvaro el Centro General de Vacunación contaba gracias al celo del gobierno con el personal y el material necesario. La dotación material se componía de un local propio, con capacidad y condiciones esenciales, así como del mobiliario, instrumentos y utensillos necesarios. Además, señalaba que se había adquirido un buen microscopio. Memoria (1876), pp. 10-11. 
físicas apropiadas para garantizar el éxito de las inoculaciones constituía una dificultad añadida ${ }^{81}$. Sin embargo, los problemas de mayor enjudia provenían de la endémica falta de calidad y cantidad de la vacuna obtenida, así como de la exigua labor vacunadora de la central madrileña ${ }^{82}$.

Estas dificultades marcaron profundamente la vida del Centro en sus primeros meses de vida. Todavía en el primer semestre de 1876 se utilizaron los restos de la vacuna de Lanoix y de Roure. El escaso éxito de la primera confirmó su degeneración, mientras que la segunda dio resultados satisfactorios hasta el mes de julio ${ }^{83}$. Al reanudarse en septiembre la temporada de vacunación, el Centro se encontró con la pérdida definitiva de la calidad de su vacuna animal, viéndose obligado a importar cow-pox del Instituto del Dr. Negri de Nápoles y del regentado por E. Warlomont en Bruselas, dando el primero el resultado apetecido ${ }^{84}$. El fluido napolitano permitió continuar con las tareas vacunadoras pero puso de relieve la dependencia del Centro General de Vacunación de las importaciones:

«En la imposibilidad, poco menos que absoluta, de encontrar en nuestra Península legítimo cow-pox en las ubres de las vacas que están criando, y siendo un hecho indisputable, comprobado más de una vez por el Centro, la pronta extinción de la virulencia en la linfa cuando ha pasado por un número no muy largo de transmisiones en la ternera o la vaca, habrá de verse por fuerza muy a menudo el Establecimiento en grandísimo apuro para conservar la vacuna animal, y en la precisión, para adquirirla nuevamente, de recurrir en demanda de virus activo a los Institutos de otras Naciones, que puedan obtenerle con frecuencia puro en la fuente misma donde lo encontró Jenner» ${ }^{85}$.

La falta de vacuna determinó que las tareas de investigación que el Centro tenía encomendadas se redujeran prácticamente a «indagar por qué medios

81 «La adquisición de terneras pequeñas, de piel fina, bien nutridas y sanas, es entre nosotros un asunto por demás rodeado de dificultades, que opone ciertamente uno de los más fuertes obstáculos al cabal y constante éxito de la inoculación, y al crédito consiguiente de la vacuna animal. Las más veces solo pueden adquirirse terneras ya grandes, ordinarias, flacas y mal cuidadas; siendo a menudo estéril por esta causa el resultado de las vacunaciones que se practican de tenera a ternera. Memoria que eleva al gobierno el Instituto de Vacunación del Estado correspondiente al año económico de 1876-1877, Madrid. Establecimiento Tipográfico de M.M. de los Rios, 1877, p. 7.

82 Memoria (1877), pp. 9-10.

83 Memoria (1876), p. 14.

84 Memoria (1877), p. 11.

85 Ibid., p. 13. 
podrá obtener la cantidad de virus vacuno exigida por las necesidades de servicio, a lograr que sea de la mejor calidad posible, y a recolectarlo y conservarlo de la manera más conveniente y segura» ${ }^{86}$. Una de la vías en las que más esperanzas depositó fue la búsqueda del horse-pox o arestin, con el objetivo de indagar si era inoculable en la ternera y si era posible «transmitir la vacuna de tal procedencia a la especie humana». Sin embargo, los experimentos llevados a cabo fueron negativos ${ }^{87}$.

La ausencia de resultados con la vacuna animal se tradujo en una cierta desesperanza hacia este método. El Centro, pese a su apuesta inicial por lograr desarrollar la vacunación animal, continuó prácticando la tradicional de brazo a brazo. De hecho a mediados de 1876, aunque los resultados obtenidos con la linfa animal eran bastante pobres y las estadísticas españolas mostraban que el sistema jenneriano era más eficaz, Méndez Alvaro apostaba por las inoculaciones de origen animal, arguyendo que:

«cuando en todas partes se afanan por encontrar el verdadero cow-pox y mantenerle en las terneras, tanto con la mira de evitar el contagio de otras enfermedades al hacer las inoculaciones de brazo en brazo, como para obtener un manantial más copioso con que ocurrir a las crecientes necesidades de la vacunación, alguna mayor estima merecen, en igualdad de casos, los resultados obtenidos con la linfa de ternera que los alcanzados con la de brazo $^{88}$.

Hay que tener en cuenta que los porcentajes de vacuna de origen animal que prendieron en $1876 \mathrm{y}$ en el primer semestre de 1877 (Tabla I y II ) fueron del $59,68 \%$ y del $72,41 \%$ respectivamente, mientras que la vacuna humanizada para el mismo periodo alcanzó porcentajes del 83,42\% y del $85,71 \%$.

Por tanto los repetidos fracasos de la linfa proveniente de la ternera y los relativos exitos de la humanizada hicieron cambiar de opinión a Méndez Alvaro hasta el punto de considerar en 1877 la necesidad de favorecer el cultivo de esta última por ser «más segura en su inmediato resultado que la animal» ${ }^{89}$ porque:

«Aun cuando pase el virus jenneriano por numerosas series humanas, está demostrado que no degenera ni pierde su benéfica actividad si el niño vacunífero reune buenas condiciones de edad y robustez, si las pústulas de donde se toma están bien desarrolladas y en el conveniente punto de madurez, y, en fin, cuando se prác-

86 Ibid., p. 18.

87 Ibid., p. 23.

88 Memoria (1876), p. 21.

89 Memoria (1877), p. 34. 
tica bien la operación. El Centro opina, por tanto que debe cultivarse en él, con igual, y aún con mayor cuidado y esmero, la vacuna de brazo que la animal, obteniendo de ambas aquella crecida cantidad de buena linfa inoculable que puede ser necesaria para la vacunación en todas las provincias del Reino.» ${ }^{90}$

El otro grave problema que padecía el Instituto, y que en buena medida derivaba del primero, era su falta de implantación en Madrid. Si se observan las tablas I y II puede comprobarse que en sus primeros 18 meses de funcionamiento se practicaron en sus instalaciones sólo 1182 vacunaciones, de las cuales 820 procedían de la ternera y 362 eran humanizadas.

\section{TABla I: VACunaciones hechas en el Centro General DE VACUNACIÓN DURANTE EL AÑO 1876}

\begin{tabular}{|l|c|c|c|c|c|c|}
\hline \multirow{2}{*}{ MESES } & \multicolumn{2}{|c|}{ PROCEDENCIA } & \multicolumn{2}{c|}{ PRENDIERON } & \multicolumn{2}{c|}{ ESTERIL } \\
\cline { 2 - 7 } & Ternera & Brazo & Ternera & Brazo & Ternera & Brazo \\
\hline Enero & 2 & 5 & 1 & 4 & 1 & 1 \\
\hline Febrero & 34 & 11 & - & 9 & 34 & 2 \\
\hline Marzo & - & - & - & - & - & - \\
\hline Abril & 22 & 19 & 17 & 17 & 5 & 2 \\
\hline Mayo & 65 & 86 & 51 & 75 & 14 & 11 \\
\hline Junio & 20 & 32 & 16 & 26 & 4 & 6 \\
\hline Julio & 4 & - & 4 & - & - & - \\
\hline Agosto & - & - & - & - & - & - \\
\hline Septiembre & 6 & - & 1 & - & 5 & - \\
\hline Octubre & 34 & 12 & 18 & 6 & 16 & 6 \\
\hline Noviembre & 45 & 22 & 32 & 19 & 13 & 3 \\
\hline Diciembre & 26 & - & 14 & - & 12 & - \\
\hline TOTALES & 258 & 187 & 154 & 156 & 104 & 31 \\
\hline
\end{tabular}

$90 \quad$ Ibid., p. 35. 
TABla II: VACUnACIONES hechas EN EL CENTRO GENERAL DE VACUNACIÓN DURANTE EL PRIMER SEMESTRE DE 1877.

\begin{tabular}{|l|c|c|c|c|c|c|}
\hline \multirow{2}{*}{ MESES } & \multicolumn{2}{|c|}{ PROCEDENCIA } & \multicolumn{2}{c|}{ PRENDIERON } & \multicolumn{2}{c|}{ ESTERIL } \\
\cline { 2 - 7 } & Ternera & Brazo & Ternera & Brazo & Ternera & Brazo \\
\hline Enero & 34 & 2 & 11 & 2 & 23 & - \\
\hline Febrero & 35 & 4 & 13 & 3 & 22 & 1 \\
\hline Marzo & 40 & - & 22 & - & 18 & - \\
\hline Abril & 112 & 64 & 81 & 55 & 31 & 9 \\
\hline Mayo & 233 & 83 & 197 & 70 & 36 & 13 \\
\hline Junio & 108 & 22 & 83 & 20 & 25 & 3 \\
\hline TOTALES & 562 & 175 & 407 & 150 & 155 & 26 \\
\hline
\end{tabular}

Los motivos alegados para justificar la baja actividad del Centro eran variopintos: no era conocido por la población debido a su reciente creación; tenía que competir con otros establecimientos, organismos y facultativos que vacunaban en la capital; tenía que hacer frente al descrédito de la vacuna animal debido a la baja calidad del fluido empleado en sus dependencias y, por último se señalaba el desinterés de la población por vacunarse.

Un asunto de primera importancia fueron los problemas para obtener una estadística fiable de las vacunaciones prácticadas en el resto de España. Los gobernadores civiles estaban obligados a enviar al Centro los datos las operaciones realizadas en su provincia. Sin embargo, los datos en la mayoría de los casos no llegaban a su destino o lo hacían parcialmente. Así en el primer semestre de 1876 sólo fueron remitidos los de 11 provincias y relativas a un mes. ${ }^{91}$ Para el segundo semestre de ese año y el primero del siguiente se recibieron los de 21 pero de manera bastante incompleta. De las 64.114 vacunaciones prácticadas en esas provincias, 10642 lo fueron con virus procedente de Madrid, 14.209 de Valencia, 11024 de Sevilla, 971 de Barcelona y 6597 eran de origen desconocido. Sin embargo, estos datos sólo señalaban el lugar de procedencia, no el establecimiento con lo cual no aclaraban el origen de la vacuna utilizada. Méndez Alvaro se refería a esta carencia en los siguientes términos:

91 Memoria (1876), p. 17. 
«Cada Establecimiento de vacunación, cada provincia, cada pueblo, cada vacunador, se proporciona el virus que puede y de donde puede; mezclanse en una provincia o pueblo los de orígenes distintos, que a su vez constituyen un nuevo manantial de virus vacuno, y resulta en definitiva que nada puede averiguarse que ofrezca mediana seguridad ni tenga estimable valor. Esos 10642 vacunados en las 21 referidas provincias con virus de Madrid, lo han podido ser con el recogido por muchos Facultativos que se dedican a la práctica de la vacunación, con el que suministran las Casas de Socorro, con el recibido por la Dirección de Beneficencia y Sanidad de la Sociedad Jenneriana de Londres, y en fin, con el cultivado y cosechado en el Centro ${ }^{92}$ 》.

Por lo tanto, a la altura de junio de 1877, el Centro General de Vacunación pese a sus objetivos fundacionales se encontraba en una situación bastante precaria en cuanto a resultados materiales y científicos se refiere. No conseguía producir y distribuir fluido vacunal suficiente; no acababa de apostar por un tipo concreto de técnica vacunífera; su actividad vacunadora en Madrid era muy baja y tenía que competir con otros establecimientos y facultativos; no disponía de una plantilla adecuada; no conseguía centralizar bien los datos procedentes de toda España y ni siquiera controlaba las vacunaciones que se prácticaban con su fluido en todo el Estado. Lejos de convertirse en un centro de referencia nacional, el Instituto era un establecimiento más de los que vacunaban en Madrid. De alguna manera se cumplían los temores que Méndez Alvaro había expuesto en las consideraciones al reglamento de 1871.

Con el objeto de paliar las graves carencias de la sede madrileña el gobierno tomó algunas medidas en julio de 1877. La primera fue cambiar una vez más la denominación del Centro que pasó a denominarse Instituto de Vacunación del Estado. La segunda, algo más profunda, lo reorganizaba, dividiéndolo en dos secciones, una central y otra visitadora. El objeto de esta división era la «necesidad de completar la organización (...) con un esmerado servicio de visita que compruebe el resultado de las operaciones prácticadas en el establecimiento y suministre los datos que han de constituir la estadística de este ramo» ${ }^{93}$. La reforma implicaba una nueva organización de la plantilla y un confuso reparto de atribuciones entre las secciones. La plantilla aprobada se incrementaba sólo en dos médicos, lo que suponía un aumento en gastos de personal de 1000 pesetas.

Por último, la reestructuración se completaba con otras disposiciones entre las que destacaba el encargo a la comisión permanente de la vacuna de la

92 Memoria (1877), p. 26.

93 ARAMM, legajo 127. Doc. 6047. 
Real Academia de Medicina de redactar un nuevo reglamento «para el régimen y gobierno del Instituto (...) con sujección a las bases que se consignan en esta orden.» lo que suponía la tercera variación del mismo en un periodo de seis años y mostraba de nuevo las enormes dificultades por las que atravesó su fundación.

Aunque tras esta última reorganización el Instituto se estabilizó y mantuvo su continuidad, siguió arrastrando los problemas que marcaron su nacimiento, sin llegar nunca a cumplir plenamente sus objetivos fundacionales. ${ }^{94}$ Todavía en 1885 y en 1887 sufrió nuevos ajustes encaminados a enderezar una tortuosa trayectoria, que nunca contó con el apoyo presupuestario necesario por parte del Estado ${ }^{95}$.

94 Después de un largo y costoso proceso, a mediados de la década de 1880, logró aclimatar definitivamente la vacuna animal y cultivarla sin problemas. Las cifras de vacunación del establecimiento de Madrid fueron aumentando paulatinamente, si bien nunca llegó a convertirse en el principal Instituto de vacunación de la capital. Las dificultades para recabar las estadísticas de las provincias todavía no estaban resueltas en 1885. Sobre estos aspectos véase: Memoria que eleva al Gobierno el Director del Instituto de Vacunación del Estado correspondiente a los cinco años de 1880 a 1884 . No hemos localizado ningún ejemplar impreso pero hemos consultado el manuscrito que se encuentra en la Academia de Medicina de Madrid. Véase el Legajo 149. Documento 7706. Desde 1887 tuvo que competir duramente con algunos establecimientos privados como el Instituto de la calle Valverde y el Instituto del Dr. Balaguer, cuyo propietario era además el director del Servicio de Vacunación Directa de la Ternera del Ayuntamiento de Madrid. Estos aspectos pueden seguirse en CAMPOS (2001); MORAL RoncAL, A, «Los comienzos de la vacunación en Madrid. (1875-1903)», Torre de los Lujanes , 1992, n 19, 1er trimestre, pp. 92-104.

95 En 1885 un Real Decreto de 20 de noviembre recortó su plantilla, que había crecido hasta 16 facultativos, un conserje y tres mozos, con el pretexto de racionalizar los gastos y favorecer el presupuesto de material. Al mismo tiempo se establecía un sistema de oposiciones públicas para acceder a la plantilla del Instituto, que dio origen al Cuerpo de Vacunadores del Estado. La información puede verse en «Sección Oficial. Ministerio de Gobernación», El Siglo Médico, 29 de noviembre de 1885, $\mathrm{n}^{\circ}$ 1666, pp. 776-777. También puede consultarse: Molero Mesa, J.; Jiménez LuCEnA, I. (2000), «Salud y Burocracia en España. Los Cuerpos de Sanidad Nacional (1855-1951)», Revista Española de Salud Pública, 74 (monográfico), 45-79, p. 56.La reforma de 1887 consistió en una nueva demanda de reorganización de la plantilla en nombre de una mayor efectividad del Instituto. Véase ARAMM, Legajo 157. Doc. 8216. 